\title{
Prognostic significance of pretreatment serum free fatty acid in patients with diffuse large B-cell lymphoma in the rituximab era: a retrospective analysis
}

\author{
Liping Fan ${ }^{1 \dagger}$, Qiuyan Lin ${ }^{1 \dagger}$, Xiaoling Huang ${ }^{1}$, Danhui Fu ${ }^{2^{*}}$ and Haobo Huang ${ }^{1 *}$
}

\begin{abstract}
Background: Fatty acid metabolism is reportedly associated with various cancers. However, the role of pretreatment serum free fatty acid (FFA) levels in diffuse large B-cell lymphoma (DLBCL) prognosis is still unclear, and our study aimed to better elucidate its influence on clinical outcomes.

Methods: The medical records of 221 newly diagnosed DLBCL patients admitted to Fujian Medical University Union Hospital from January 2011 to December 2016 were analysed retrospectively. Receiver operating characteristic curve analysis was used to determine a cut-off value for pretreatment serum FFA levels for prognostic prediction in DLBCL patients. The relationship between pretreatment serum FFA levels and clinical and laboratory parameters was analysed. Univariate and multivariate analyses were used to assess prognostic factors for overall survival (OS) and progression-free survival (PFS).

Results: Newly diagnosed DLBCL patients with high pretreatment serum FFA levels ( $\geq 0.495 \mathrm{mmol} / \mathrm{l})$ had more B symptoms, higher serum lactate dehydrogenase levels ( $>$ upper limit of normal), $>1$ extranodal site, and higher International Prognostic Index score (3-5) compared to those with low pretreatment serum FFA levels $(<0.495$ $\mathrm{mmol} / \mathrm{l})$. Higher serum FFA levels were independent prognostic factors for poor OS, but not PFS.
\end{abstract}

Conclusions: High pretreatment serum FFA levels are associated with lower survival in untreated DLBCL patients.

Keywords: DLBCL, Free fatty acid, Prognostic factor

\footnotetext{
*Correspondence: fudanhui@189.cn; huanghaobo1981@163.com

${ }^{\dagger}$ Liping Fan and Qiuyan Lin contributed equally to this work.

${ }^{2}$ Fujian Institute of Hematology, Fujian Provincial Key Laboratory on Hematology, Department of Hematology, Fujian Medical University Union Hospital, Gulou District, Fuzhou City 350001, Fujian Province, China 'Department of Blood Transfusion, Fujian Medical University Union Hospital, Gulou District, Fuzhou City 350001, Fujian Province, China
}

(c) The Author(s). 2021 Open Access This article is licensed under a Creative Commons Attribution 4.0 International License, which permits use, sharing, adaptation, distribution and reproduction in any medium or format, as long as you give appropriate credit to the original author(s) and the source, provide a link to the Creative Commons licence, and indicate if changes were made. The images or other third party material in this article are included in the article's Creative Commons licence, unless indicated otherwise in a credit line to the material. If material is not included in the article's Creative Commons licence and your intended use is not permitted by statutory regulation or exceeds the permitted use, you will need to obtain permission directly from the copyright holder. To view a copy of this licence, visit http://creativecommons.org/licenses/by/4.0/. The Creative Commons Public Domain Dedication waiver (http://creativecommons.org/publicdomain/zero/1.0/) applies to the data made available in this article, unless otherwise stated in a credit line to the data. 


\section{Background}

Diffuse large B-cell lymphoma (DLBCL) is the most common type of B-cell non-Hodgkin's lymphoma (NHL), accounting for $30-40 \%$ of all NHLs worldwide. Currently, the first-line regimen is the anti-CD20 monoclonal antibody rituximab plus cyclophosphamide, doxorubicin, vincristine, and prednisone. However, the heterogeneity in immunology, cytogenetics, and molecular biology of DLBCL patients lead to diverse clinical outcomes. Moreover, 40-50\% of the patients suffer from relapsed or refractory DLBCL [1-3]. Therefore, treatment should be based on risk stratification.

The earliest prognostic index for NHL was the International Prognostic Index (IPI) score, which was established before the wide application of rituximab in clinical practice and had been based on clinical factors, including age, Ann Arbor stage, extranodal disease, Eastern Cooperative Oncology Group (ECOG) score, and serum lactate dehydrogenase (LDH) level. The addition of rituximab to the standard chemotherapy regimen has dramatically improved the outcomes of DLBCL patients; however, several studies showed that the IPI could not effectively predict the prognosis of DLBCL patients. Since then, the revised IPI and the National Comprehensive Cancer Network IPI (NCCNIPI) were generated $[4,5]$. Nevertheless, none of these indexes could precisely predict DLBCL patient prognosis $[6,7]$. Therefore, it is necessary to identify other factors in patients with DLBCL as predictors of prognosis.

Abnormal lipid metabolism is considered to be an important feature of tumor development and progression $[8,9]$. Some researchers demonstrated that abnormal lipid metabolism occurred in DLBCL patients as well as in cell lines $[10,11]$. Free fatty acids (FFAs) are an important energy source for cells and bind to albumin in the blood. Some studies showed that abnormal serum FFA levels were associated with poor prognosis in several types of malignancy, such as prostate cancer, lung cancer, gastric cancer, thyroid cancer, colorectal cancer, and ovarian cancer [12, 13]. However, the association between serum FFA levels and DLBCL is still unclear. Therefore, we retrospectively analysed the data of DLBCL patients in our hospital, intending to evaluate the prognostic value of pretreatment serum FFAs.

\section{Methods}

\section{Patient selection}

This study was conducted in accordance with the Declaration of Helsinki (as revised in 2013). The study design was approved by the Ethics Committee of Fujian Medical University Union Hospital. As this study was a retrospective data analysis and did not affect patients' treatments, written informed consent was not sought.
We studied 361 newly diagnosed DLBCL patients who were admitted to Fujian Medical University Union Hospital from January 1, 2011, to December 31, 2016. Patients who were $\geq 14$ years old and received $\geq 4$ cycles of immunochemotherapy were included in the study. All patients were diagnosed according to the World Health Organization classification. Patients diagnosed with primary mediastinal lymphoma, primary central nervous system lymphoma, human immunodeficiency virus infection, or diabetes mellitus were excluded. Clinical and laboratory parameters, including age, sex, B symptoms, serum LDH levels, ECOG score, Ann Arbor stage, extranodal disease sites, IPI score, cell of origin, serum FFAs levels, and immunochemotherapy regimens, were collected from medical records. Based on the screening flowchart depicted in Fig.1, a total of 221 patients were included in the analysis.

\section{Sample detection}

Peripheral blood samples were collected from all patients within a week before the primary therapy. Peripheral blood samples collected from 221 healthy individuals without metabolic and neoplastic diseases, presenting in the same time period, sex- and agematched to the DLBCL cases were designated as the normal control group. All samples were collected from the patients and healthy individuals after a night of fasting.

The serum FFAs that we measured were non-esterified fatty acids. FFAs were detected by the enzymatic endpoint method using an automatic biochemical analyser according to the manufacturer's instructions. Detection reagents were purchased from FUJIFILM Wako Pure Chemical Corporation (Japan).

\section{Treatment and follow-up}

The 221 patients included in this study had received $\geq 4$ cycles of immunochemotherapy consisting of cyclophosphamide, doxorubicin or epirubicin, vincristine, prednisone, and rituximab, with or without a history of tissue biopsy or surgical excision.

Treatment response evaluation was performed according to the International Working Group Response Criteria for Malignant Lymphoma through laboratory tests and imaging examinations with or without bone marrow biopsy [14]. When disease progression or relapse occurred, patients were treated with later-line regimens recommended by the NCCN guidelines [15-17].

Overall survival (OS) was defined as the time from the date of diagnosis to the date of death due to any cause or the last follow-up. Progression-free survival (PFS) was defined as the time from the date of diagnosis to the date of disease progression, relapse, or death, whichever came first. The last date of follow-up was June 10, 2019. 


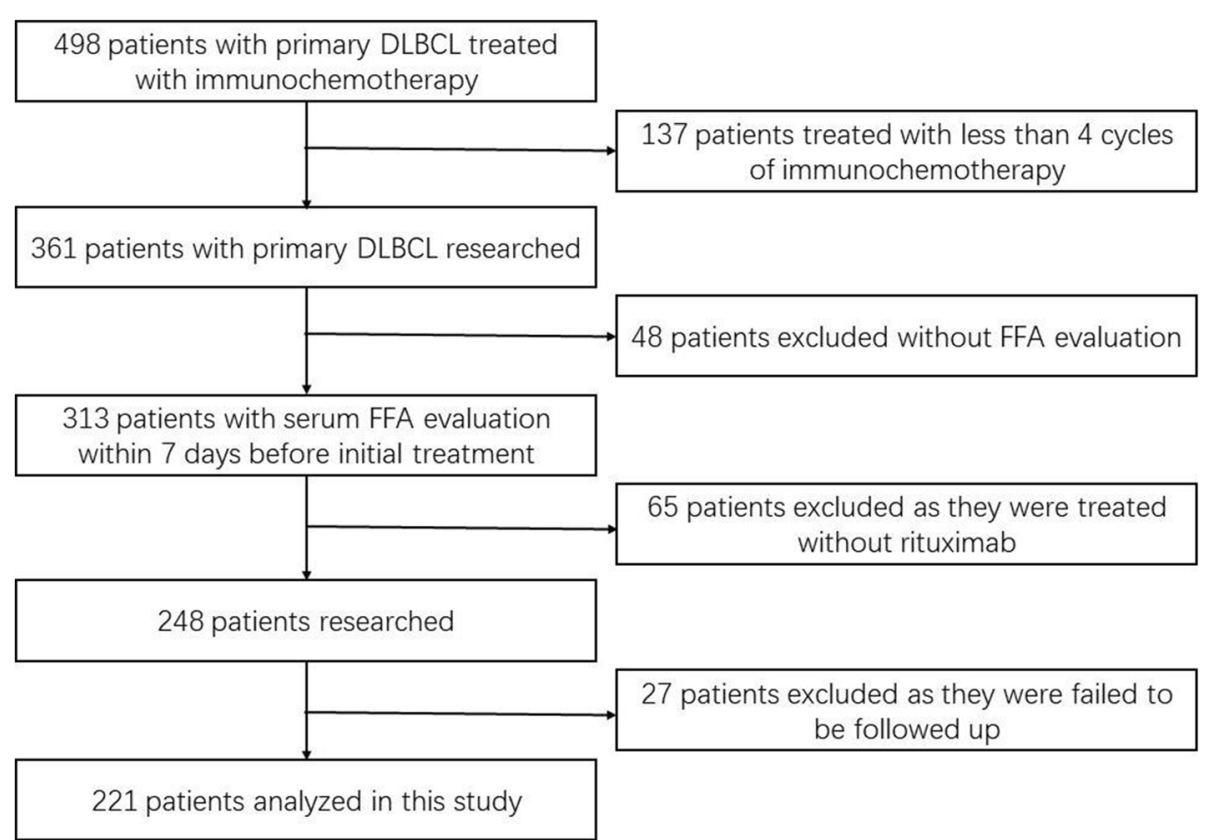

Fig. 1 A flowchart showing retrospective screening for DLBCL patients

Follow-up data were obtained from clinical records or by telephone interviews with the patients or their relatives.

\section{Statistical analyses}

All statistical analyses were performed using SPSS version 19.0 software (SPSS, Inc. Chicago, IL, USA) for Windows. The receiver operating characteristic (ROC) curve was used to determine the optimal cut-off value for FFAs. Serum FFAs levels were compared to clinical and laboratory parameters using the Chi-square test. The Kaplan-Meier method was applied for the analysis of time-to-event data. The Cox proportional hazard model was used for the univariate analysis of potential survival predictors. The stepwise forward Cox regression model was used for multivariate analysis of statistically significant clinical variables determined from the univariate analysis. The Log-rank test was used to compare the survival time of the different groups. A two-sided $P$ value $<0.05$ was considered statistically significant.

\section{Results}

\section{Patients' characteristics}

From January 2011 to December 2016, 221 patients with newly diagnosed DLBCL who met the inclusion criteria were enrolled in this study (Table 1). This cohort consisted of 128 (57.92\%) males and 93 (42.08\%) females. The median age at diagnosis was 54 years (range: 14$86)$, with $72(32.58 \%)$ patients being $>60$ years old. In this cohort, 57 (25.79\%) patients had B symptoms, 102
(46.15\%) had higher (>upper limit of normal) LDH levels, 50 (22.62\%) had high ECOG scores (2-4), and 139 $(62.90 \%)$ had advanced cancer stages (III-IV). The number of patients with IPI scores corresponding to low-risk (0-1), low-intermediate-risk (2), high-intermediate risk (3), and high-risk (4-5) were 88 (39.82\%), 54 (24.44\%), $50(22.62 \%)$, and $29(13.12 \%)$, respectively. The diagnostic tissue samples of 23 patients were insufficient to determine the cell of origin. The cell of origin for 76 (34.39\%) patients was the germinal center B-cell (GCB), and $122(55.20 \%)$ patients were non-GCB.

\section{Serum FFA levels in DLBCL patients and healthy individuals}

Pretreatment serum FFA levels in DLBCL patients ranged from $0.02-1.38 \mathrm{mmol} / \mathrm{l}$ with a median value of $0.51 \mathrm{mmol} / \mathrm{l}$. Serum FFA levels in healthy individuals ranged from $0.09-0.96 \mathrm{mmol} / \mathrm{l}$ with a median value of $0.3 \mathrm{mmol} / \mathrm{l}$. The results showed that serum FFA levels in DLBCL patients were significantly higher than those in healthy individuals $(0.535 \pm 0.017$ vs. $0.319 \pm 0.009)$ (Fig.2).

\section{Identification of optimal FFA cut-off values and patient outcomes}

The optimal FFA cut-off value determined by the ROC curve was $0.495 \mathrm{mmol} / \mathrm{l}$, with an area under the curve value of 0.602 (95\% CI, 0.510-0.694, $P=0.038$ ) (Fig.3). In this cohort, 115 (52.04\%) patients were assigned to the high FFAs group and 106 (47.96\%) to the low FFAs group. 
Table 1 Demographic and clinical parameters of enrolled patients $(n=221)$

\begin{tabular}{|c|c|c|c|c|}
\hline \multirow[t]{2}{*}{ Parameters } & \multirow[t]{2}{*}{ Classification } & \multicolumn{2}{|l|}{ FFAs } & \multirow[t]{2}{*}{$P$} \\
\hline & & $\operatorname{Low}(n=106)$ & $\operatorname{High}(n=115)$ & \\
\hline \multirow[t]{2}{*}{ Age (years) } & $>60$ & $32(30.19 \%)$ & $40(34.78 \%)$ & 0.477 \\
\hline & $\leq 60$ & $74(69.81 \%)$ & 75 (65.22\%) & \\
\hline \multirow[t]{2}{*}{ Sex } & Male & 65 (61.32\%) & $63(54.78 \%)$ & 0.343 \\
\hline & Female & 41 (38.68\%) & 52 (45.22\%) & \\
\hline \multirow[t]{2}{*}{ B symptoms } & Absent & $88(83.02 \%)$ & 76 (66.09\%) & 0.005 \\
\hline & Present & $18(16.98 \%)$ & 39 (33.91\%) & \\
\hline \multirow[t]{2}{*}{$\mathrm{LDH}$} & $>$ ULN & 31 (29.25\%) & $71(61.74 \%)$ & $<0.001$ \\
\hline & Normal & 75 (70.75\%) & $44(38.26 \%)$ & \\
\hline \multirow[t]{2}{*}{ ECOG score } & $0-1$ & $88(83.02 \%)$ & $83(72.17 \%)$ & 0.076 \\
\hline & $2-4$ & $18(16.98 \%)$ & 32 (27.83\%) & \\
\hline \multirow[t]{2}{*}{ Ann Arbor Stage } & $|-| \mid$ & $44(41.51 \%)$ & 38 (33.04\%) & 0.212 \\
\hline & III-IV & $62(58.49 \%)$ & 77 (66.96\%) & \\
\hline Extranodal & $>1$ & $23(21.70 \%)$ & $41(35.65 \%)$ & 0.026 \\
\hline disease & $\leq 1$ & $83(78.30 \%)$ & $74(64.35 \%)$ & \\
\hline \multirow[t]{4}{*}{$\mid \mathrm{PI}$} & Low risk (0-1) & $52(49.06 \%)$ & $36(31.30 \%)$ & 0.008 \\
\hline & Low-intermediate risk (2) & $28(26.42 \%)$ & $26(22.61 \%)$ & \\
\hline & High-intermediate risk (3) & $16(15.09 \%)$ & $34(29.57 \%)$ & \\
\hline & High risk (4-5) & $10(9.43 \%)$ & 19 (16.52\%) & \\
\hline \multirow[t]{3}{*}{ Cell of origin } & GCB & $36(33.96 \%)$ & $40(34.78 \%)$ & 0.416 \\
\hline & non-GCB & 56 (52.83\%) & 66 (57.39\%) & \\
\hline & Undetermined & $14(13.21 \%)$ & $9(7.83 \%)$ & \\
\hline
\end{tabular}

The clinical and laboratory parameters, as well as the comparison between the high FFAs and low FFAs groups, are shown in Table 1. Patients in the high FFAs group had more B symptoms $(33.91 \%$ vs. $16.98 \%, P=0.005$ ), higher LDH level (>upper limit of normal) $(61.74 \%$ vs. $29.25 \%, P<0.001)$, more cases of
$>1$ extranodal site $(35.65 \%$ vs. $21.70 \%, P=0.026)$ and higher IPI (3-5) (46.09\% vs. $24.52 \%, P=0.007)$ than those in the low FFAs group. There were no statistically significant differences in age, sex, ECOG score, Ann Arbor stage, and cell of origin between these two groups.

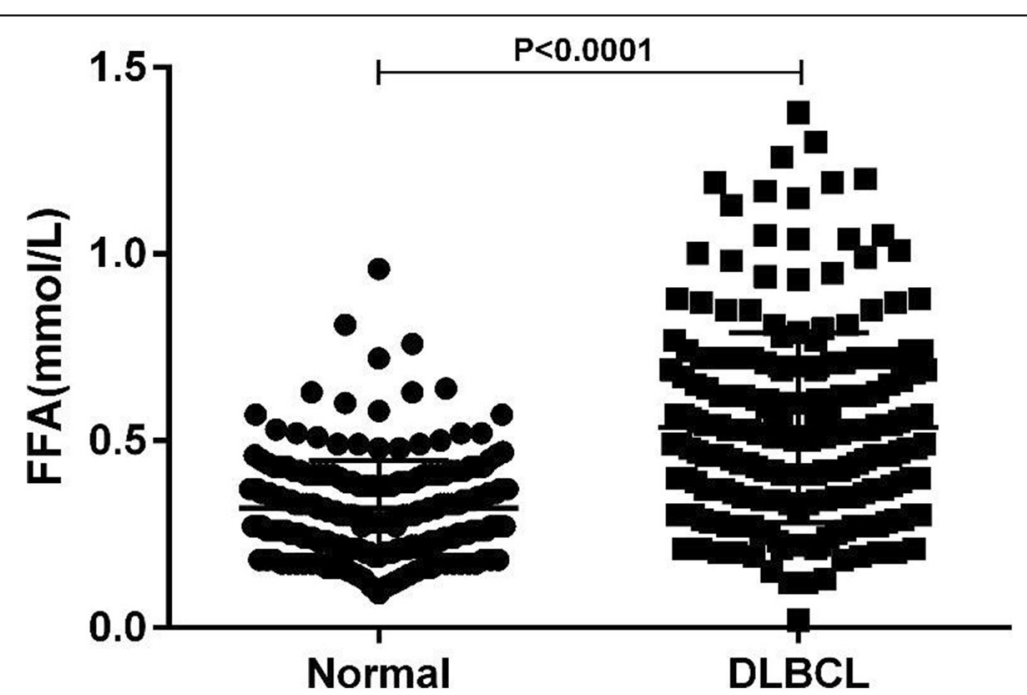

Fig. 2 Serum FFAs level in DLBCL patients and healthy individuals 


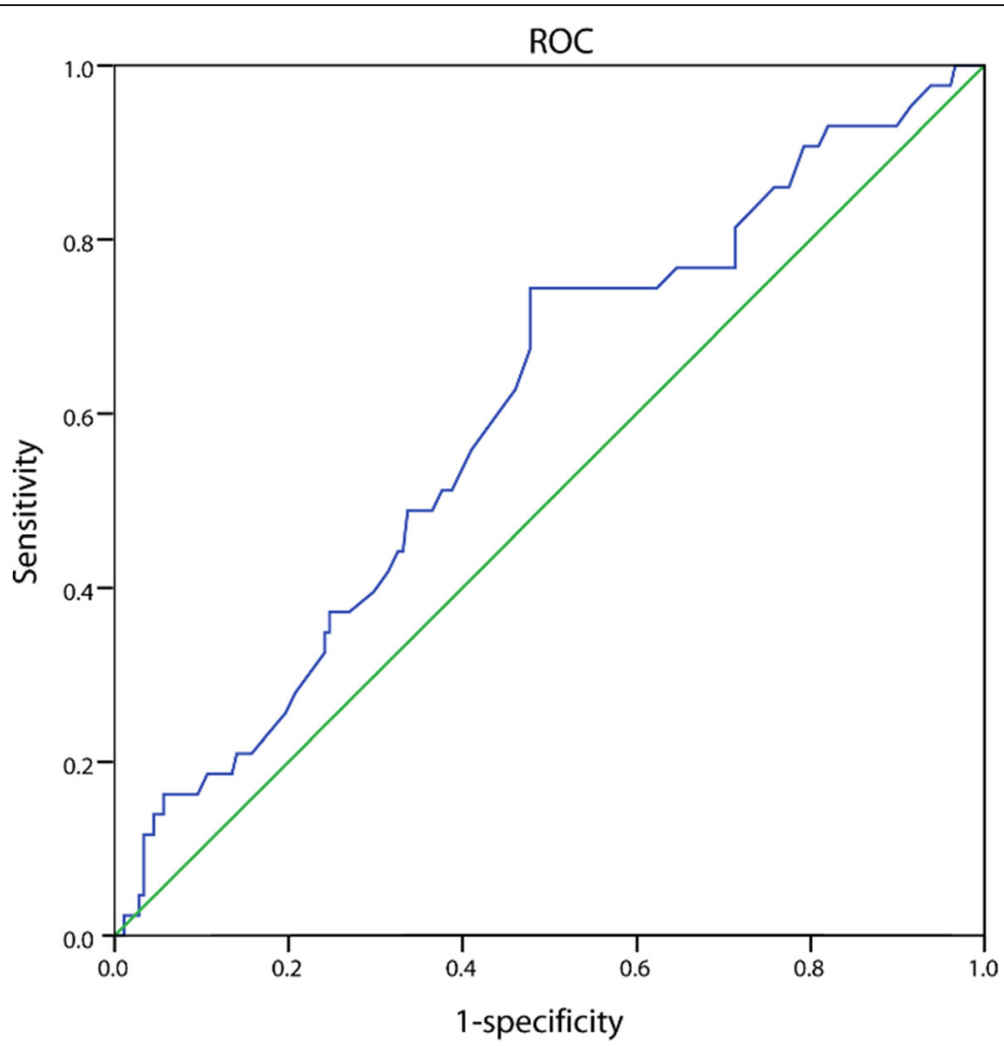

Fig. 3 ROC curve analysis of pretreatment serum FFAs levels ( $A \cup C=0.602,95 \% \mathrm{Cl} 0.510-0.694, P=0.038$ )

\section{Univariate and multivariate analyses of potential prognostic factors for survival}

The median follow-up period of this cohort was 45.03 months (range: 2.93-96.3 months), and 43 patients died. The median OS and PFS were not reached in this cohort.

Univariate analysis showed that higher serum FFA levels $(\geq 0.495 \mathrm{mmol} / \mathrm{l})(P=0.004)$, as well as the presence of B symptoms $(P=0.007)$, elevated LDH $(P<0.001)$, ECOG score $\geq 2(P=0.001),>1$ extranodal site $(P=0.016)$, and high-intermediate risk (3) or high-risk (4-5) IPI score $(P=0.001$ and $P<0.001$, respectively) were significantly associated with shorter OS. Multivariate analysis showed that higher serum FFA levels $(\geq 0.495 \mathrm{mmol} / \mathrm{l})$ $(P=0.036)$ and high IPI score $(P=0.001)$ were independent prognostic factors for shorter OS (Table 2, Fig.4).

On the other hand, univariate analysis showed that higher serum FFA levels $(\geq 0.495 \mathrm{mmol} / \mathrm{l})(P=0.009)$, as well as elevated LDH $(P=0.003)$, ECOG score $\geq 2(P=$ 0.007), advanced Ann Arbor Stage (III-IV) $(P=0.01),>1$ extranodal site $(P=0.006)$, and high-intermediate risk (3) or high-risk (4-5) IPI score (both $P<0.001$ ) were significantly associated with shorter PFS. Multivariate analysis showed that high IPI score $(P=0.001)$ was an independent prognostic factor for shorter PFS (Table 3, Fig.4).

\section{Discussion}

Outcomes after the first-line treatment vary for DLBCL patients; therefore, precise risk stratification is important for the choice of treatment and prognosis. However, The IPI and its derivatives are imprecise in predicting the overall outcome of DLBCL patients [4-7]. Hence, identifying specific and universal clues related to cancer development and progression is crucial to help construct useful prognostic indexes.

Metabolic reprogramming is one of the hallmarks of cancer. Metabolism-related genes, processes, and metabolites have essential roles in cancer development and progression $[8,9]$. Abnormal lipid metabolism has a significant association with the progression of hematological and other malignancies $[10,11,18-24]$. Furthermore, statins have demonstrated synergistic antitumor effects in vitro and have improved the survival of patients with several types of cancer, such as DLBCL, bladder cancer, breast cancer, lung cancer, adrenocortical cancer, and T-lymphoma [25-31]. Therefore, studies focusing on the important molecules or pathways related to lipid metabolism will be helpful in the development of new DLBCL diagnostic biomarkers or therapeutic targets.

FFAs, also named non-esterified fatty acids, largely originate from the lipolysis of triacylglycerol stored in 
Table 2 Univariate and multivariate analysis of prognostic factors for OS in patients with DLBCL

\begin{tabular}{|c|c|c|c|c|}
\hline \multirow[t]{2}{*}{ Parameters } & \multirow{2}{*}{$\begin{array}{l}\text { Univariate analysis } \\
\mathrm{HR}(95 \% \mathrm{Cl})\end{array}$} & \multicolumn{3}{|c|}{ Multivariate analysis } \\
\hline & & $\mathbf{P}$ & HR $(95 \% \mathrm{Cl})$ & $\mathbf{P}$ \\
\hline Age (>60 vs $\leq 60)$ & $1.567(0.850-2.891)$ & 0.150 & & \\
\hline Sex (male vs female) & $1.008(0.550-1.848)$ & 0.980 & & \\
\hline B symptoms (present vs absent) & $2.302(1.255-4.221)$ & 0.007 & & \\
\hline LDH (>ULN vs normal) & $4.022(2.026-7.984)$ & $<0.001$ & & \\
\hline ECOG score (2-4 vs 0-1) & $2.785(1.518-5.108)$ & 0.001 & & \\
\hline Ann Arbor Stage (III-IV vs I-II) & 1.919 (0.967-3.810) & 0.062 & & \\
\hline Extranodal disease $(>1$ vs $\leq 1)$ & $2.089(1.144-3.815)$ & 0.017 & & \\
\hline IPI & & $<0.001$ & & $<0.001$ \\
\hline Low risk (0-1) & reference & & reference & \\
\hline Low-intermediate risk (2) & $1.146(0.408-3.219)$ & 0.797 & $1.144(0.407-3.215)$ & 0.798 \\
\hline High-intermediate risk (3) & $4.044(1.763-9.276)$ & 0.001 & 3.516 (1.519-8.139) & 0.003 \\
\hline High risk (4-5) & $5.441(2.324-12.739)$ & $<0.001$ & $4.722(1.999-11.154)$ & $<0.001$ \\
\hline Subtype (GCB vs non-GCB) & $1.254(0.795-1.979)$ & 0.331 & & \\
\hline FFAs (high vs normal) & $2.698(1.385-5.258)$ & 0.004 & $2.075(1.051-4.096)$ & 0.035 \\
\hline
\end{tabular}

the adipose tissue. These fatty acids are composed mainly of oleic acid, palmitic acid, and linoleic acid. In cells, fatty acids accompanied by fatty acid-binding proteins (FABPs) are transferred to some compartments to function, such as mitochondria and peroxisome for $\beta$ oxidation, endoplasmic reticulum for trafficking and signaling and membrane synthesis, and nucleus to regulate the transcription of genes such as PPAR, FABPs, VEGF and PDK1. Therefore, FFAs can act as sources of energy, substrates for membrane structures, and precursors of several intracellular signaling molecules in cells [32, 33]. Recent researches have shown that fatty acid metabolism has an important role in determining the fate of cancer cells.

Fatty acid metabolism in humans is affected by many factors, including endocrine metabolic diseases, diet, and pregnancy. Zhang et al. have reported serum FFA levels with a median value of $0.41 \mathrm{mmol} / \mathrm{L}$ (IQR $25^{\text {th }}-75^{\text {th }}$, $0.29-0.56)$ in the normal population [13]. This result differed from our finding, probably because fatty acid metabolism varies according to age, and the age range of the normal population in our study (14-86 years) differed from that in the study by Zhang et al. (18-65 years). Abnormal serum FFA levels were usually found in patients with metabolic diseases, such as diabetes and hyperthyroidism, and more recently, in association with some malignancies $[10,11,18-24]$. Studies that have uncovered the relationship between FFAs and cancer also identified the cut-off value of serum FFAs according to cancer diagnosis [12, 13, 34]. However, it should be noted that the cut-off values of serum FFAs in different studies or different cancer types are varied. Furthermore, few studies have been reported about the relationship between pretreatment serum FFAs levels and DLBCL development and progression. Although Thanarajasingam et al. found that low levels of plasma Omega-3 fatty acid, a kind of FFA, were associated with inferior eventfree survival in untreated DLBCL patients [35], our impression was that the prognostic efficacy of serum Omega-3 fatty acid levels in DLBCL patients was limited due to the small sample size of the study. Therefore, we sought to investigate serum FFAs levels and their association with the prognosis of untreated DLBCL patients in a larger DLBCL patient population.

The main characteristics of patients included in our study were similar to previous studies. However, the median age of our cohort was 54 years, which was lower than that in other studies. The main cause of this difference could be that $\geq 14$-year-old adolescent patients enrolled in our study received the same therapeutic regimens as adult patients. Interestingly, we found that serum FFA levels in DLBCL patients were higher than those in healthy individuals. To explore the prognostic value of serum FFAs in patients with newly diagnosed DLBCL, we first identified the optimal cut-off value of pretreatment serum FFA levels according to the patients' survival. Then, we analyzed the relationships between pretreatment serum FFA levels and the clinical and laboratory parameters of patients with newly diagnosed DLBCL. Our data showed that DLBCL patients with high pretreatment serum FFA levels had more B symptoms, higher serum LDH levels, more extranodal sites, and higher IPI scores than those with low pretreatment serum FFA levels. Although previous studies report that age and sex may be potential confounding factors in assessing the risk for metabolic disturbance using FFAs 


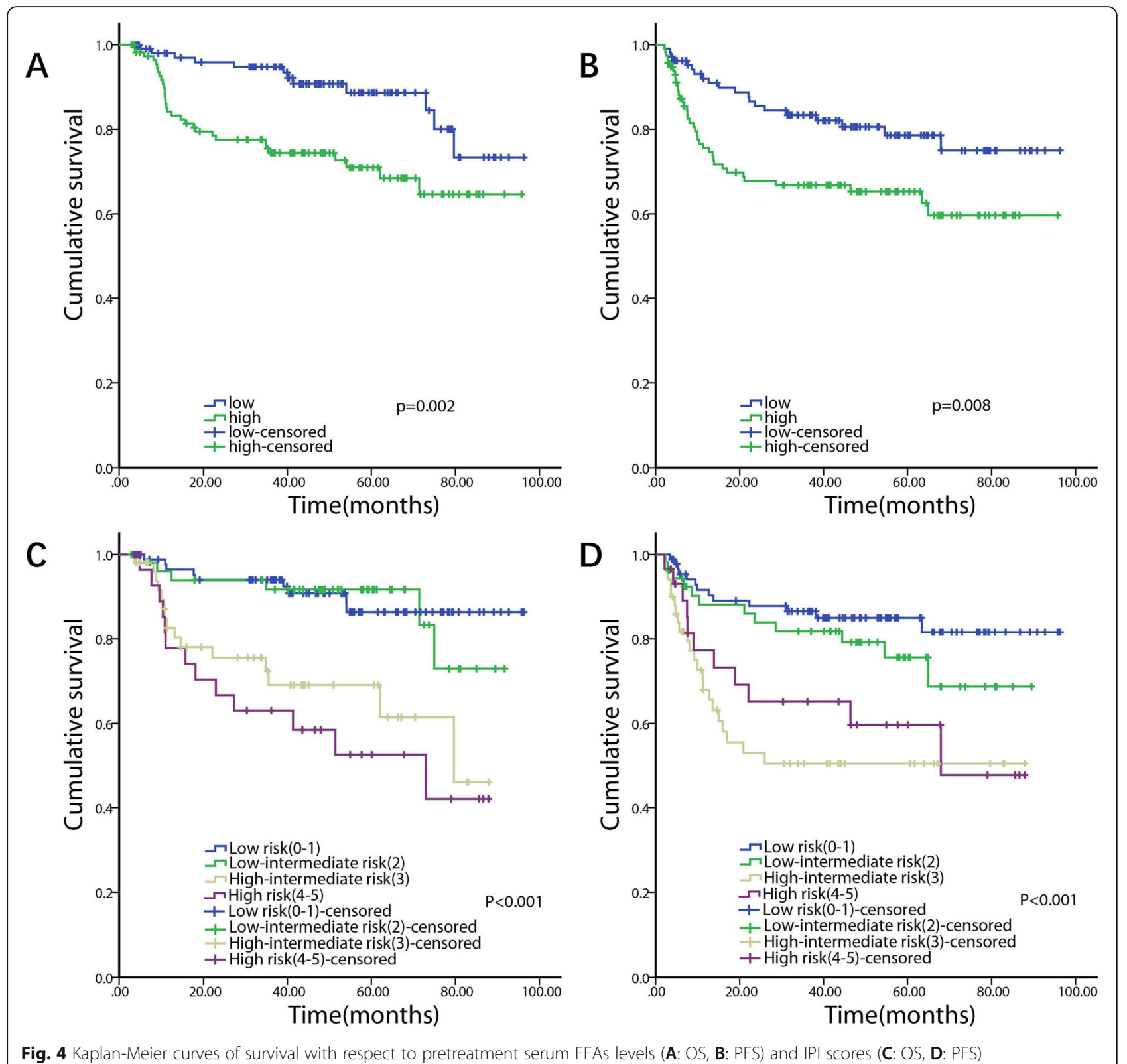

biomarkers [34], our results showed that there was no difference in pretreatment serum FFAs among DLBCL patients who belonged to different age or sex groups. This finding supports the possibility of using serum FFAs as a biomarker for the prognosis of DLBCL patients. On the other hand, univariate and multivariate analyses showed that IPI scores, in addition to higher pretreatment serum FFA levels, were independent poorprognosis factors for OS in patients with newly diagnosed DLBCL. The other parameters considered to be significant factors through univariate analysis, such as ECOG score, and serum LDH levels, were components of the IPI score. Therefore, since the predictive value of these parameters had already been included in the IPI score, they could not act as independent prognostic factors for OS in patients with newly diagnosed DLBCL.

Nevertheless, we would like to acknowledge some limitations in our study. The number of patients included in our study was insufficient for division into two sets, a training set and a validation set, to confirm our conclusions. Furthermore, the cut-off value of pretreatment serum FFAs from our single-centre study may not be applicable for analysis in other centres; it is necessary to set up a universal cut-off value for DLBCL patients from different centres. Moreover, we detected more than a single kind of FFA. This may be the reason for the relatively low sensitivity and specificity of FFAs. Further investigation is required to distinguish the kinds of FFAs 
Table 3 Univariate and multivariate analysis of prognostic factors for PFS in patients with DLBCL

\begin{tabular}{|c|c|c|c|c|}
\hline \multirow[t]{2}{*}{ Parameters } & \multicolumn{2}{|l|}{ Univariate analysis } & \multicolumn{2}{|c|}{ Multivariate analysis } \\
\hline & HR $(95 \% \mathrm{Cl})$ & $\mathbf{P}$ & HR $(95 \% \mathrm{Cl})$ & $\mathbf{P}$ \\
\hline Age (>60 vs $\leq 60)$ & $1.282(0.745-2.204)$ & 0.370 & & \\
\hline Sex (male vs female) & $0.927(0.552-1.555)$ & 0.773 & & \\
\hline B symptoms (present vs absent) & $1.421(0.815-2.480)$ & 0.216 & & \\
\hline LDH (>ULN vs normal) & $2.260(1.329-3.843)$ & 0.003 & & \\
\hline ECOG score (2-4 vs 0-1) & $2.111(1.228-3.630)$ & 0.007 & & \\
\hline Ann Arbor Stage (III-IV vs I-II) & $2.253(1.214-4.179)$ & 0.010 & & \\
\hline Extranodal disease $(>1$ vs $\leq 1)$ & $2.063(1.226-3.472)$ & 0.006 & & \\
\hline $\mid \mathrm{PI}$ & & $<0.001$ & & $<0.001$ \\
\hline Low risk (0-1) & reference & & reference & \\
\hline Low-intermediate risk (2) & $1.592(0.726-3.490)$ & 0.245 & $1.592(0.726-3.490)$ & 0.245 \\
\hline High-intermediate risk (3) & $4.238(2.127-8.444)$ & $<0.001$ & $4.238(2.127-8.444)$ & $<0.001$ \\
\hline High risk (4-5) & $3.140(1.406-7.012)$ & 0.005 & $3.140(1.406-7.012)$ & 0.005 \\
\hline Subtype (GCB vs non-GCB) & $1.151(0.774-1.711)$ & 0.487 & & \\
\hline FFAs (high vs normal) & $2.050(1.193-3.525)$ & 0.009 & & \\
\hline
\end{tabular}

that are associated with the prognosis of DLBCL patients, and to determine the specific metabolic pathways involved in this pathophysiological process. Finally, although patients with diabetes mellitus were excluded from our study, patients with impaired glucose tolerance were included. This abnormal metabolism might have introduced a potential bias in our analysis. Based on the limitations described above, a multicentre, prospective, and larger study is needed to discover and validate novel lipid metabolism-related molecular markers or pathways in DLBCL development and progression.

\section{Conclusions}

We demonstrated the clinical significance of pretreatment serum FFA levels in patients with newly diagnosed DLBCL. Our results indicated that a high pretreatment serum FFA level was associated with adverse features such as the presence of B symptoms, higher serum LDH levels, >1 extranodal sites, and a higher IPI score. Survival analysis also demonstrated that higher pretreatment serum FFAs were associated with lower survival in untreated DLBCL patients. These findings indicate that abnormal lipid metabolism may contribute to DLBCL development and progression. Focusing on lipid metabolism will be helpful in discovering further diagnostic and therapeutic targets for patients with DLBCL.

\section{Abbreviations}

DLBCL: Diffuse large B-cell lymphoma; NHL: Non-Hodgkin's lymphoma; IPI: International Prognostic Index; ECOG: Eastern Cooperative Oncology Group; LDH: Lactate dehydrogenase; NCCN: National Comprehensive Cancer Network; FFAs: Free Fatty Acids; OS: Overall survival; PFS: Progression-free survival; ROC: Receiver operating characteristic; GCB: Germinal center B-cell; ULN: Upper limit of normal; FABPs: Fatty acid-binding proteins

\section{Acknowledgements}

Not applicable.

Authors' contributions

$\mathrm{HBH}, \mathrm{LPF}$ and QYL wrote and edited the manuscript; DHF provided study material or patients; $H B H, L P F, D H F$ and XLH analysed and interpreted the data; all authors reviewed and approved the manuscript.

\section{Funding}

This work was supported by Fujian Provincial Health Technology Project (grant numbers 2019-CX-15 and 2018-CXB-7); the Joint Funds for the Innovation of Science and Technology, Fujian province (grant numbers 2019 Y9050 and 2018Y9007); the Natural Science Foundation of Fujian Province (grant numbers 2020J01992).

\section{Availability of data and materials}

All data generated or analysed during this study are included in this published article.

\section{Declarations}

Ethics approval and consent to participate

The present study was approved by the Ethics Committee of Fujian Medical University Union Hospital (2019KJCX047). The consent from patients to participate in this study was waived since the present study assessed retrospective data and did not affect the treatments of patients.

\section{Consent for publication}

Not applicable.

\section{Competing interests}

The authors declare that they have no competing interests. The funding bodies played no role in the design of the study and collection, analysis, and interpretation of data and in writing the manuscript.

Received: 19 September 2020 Accepted: 4 November 2021

Published online: 21 November 2021

\section{References}

1. Crump M, Neelapu SS, Farooq U, Van Den Neste E, Kuruvilla J, Westin J, et al. Outcomes in refractory diffuse large B-cell lymphoma: results from the international SCHOLAR-1 study. Blood. 2017;130(16):1800-8. 
2. Ayers EC, Li S, Medeiros L, Bond DA, Maddocks KJ, Torka P, et al. Outcomes in patients with aggressive B-cell non-Hodgkin lymphoma after intensive frontline treatment failure. Cancer. 2020;126(2):293-303.

3. Swerdlow SHCE, Harris NL, et al. WHO Classification of Tumours of Haematopoietic and Lymphoid Tissues. Lyon, France: IARC Press; 2008.

4. Zhou Z, Sehn LH, Rademaker AW, Gordon LI, Lacasce AS, Crosby-Thompson A, et al. An enhanced International Prognostic Index (NCCN-IPI) for patients with diffuse large B-cell lymphoma treated in the rituximab era. Blood. 2014; 123(6):837-42

5. Sehn LH, Berry B, Chhanabhai M, Fitzgerald C, Gill K, Hoskins P, et al. The revised International Prognostic Index (R-IPI) is a better predictor of outcome than the standard IPI for patients with diffuse large B-cell lymphoma treated with R-CHOP. Blood. 2007;109(5):1857-61.

6. Ruppert AS, Dixon JG, Salles G, Wall A, Cunningham D, Poeschel V, et al. International prognostic indices in diffuse large B-cell lymphoma: a comparison of IPI, R-IPI, and NCCN-IPI. Blood. 2020;135(23):2041-8.

7. Montalban C, Diaz-Lopez A, Dlouhy I, Rovira J, Lopez-Guillermo A, Alonso S, et al. Validation of the NCCN-IPI for diffuse large B-cell lymphoma (DLBCL): the addition of beta2 -microglobulin yields a more accurate GELTAMO-IPI. Br J Haematol. 2017;176(6):918-28.

8. Upadhyay M, Samal J, Kandpal M, Singh OV, Vivekanandan P. The Warburg effect: insights from the past decade. Pharmacol Ther. 2013;137(3):318-30.

9. Hanahan D, Weinberg RA. Hallmarks of cancer: the next generation. Cell. 2011;144(5):646-74.

10. Gao R, Liang JH, Wang L, Zhu HY, Wu W, Cao L, et al. Low serum cholesterol levels predict inferior prognosis and improve NCCN-IPI scoring in diffuse large B cell lymphoma. Int J Cancer. 2018;143(8):1884-95.

11. Barre FPY, Claes BSR, Dewez F, Peutz-Kootstra C, Munch-Petersen HF, Gronbaek K, et al. Specific Lipid and Metabolic Profiles of R-CHOP-Resistant Diffuse Large B-Cell Lymphoma Elucidated by Matrix-Assisted Laser Desorption lonization Mass Spectrometry Imaging and in Vivo Imaging. Anal Chem. 2018;90(24):14198-206.

12. Zhou X, Mei H, Agee J, Brown T, Mao J. Racial differences in distribution of fatty acids in prostate cancer and benign prostatic tissues. Lipids Health Dis. 2019;18(1):189.

13. Zhang L, Han L, He J, Lv J, Pan R, Lv T. A high serum-free fatty acid level is associated with cancer. J Cancer Res Clin Oncol. 2020;146(3):705-10.

14. Cheson BD, Pfistner B, Juweid ME, Gascoyne RD, Specht L, Horning SJ, et al. Revised response criteria for malignant lymphoma. J Clin Oncol. 2007;25(5): 579-86.

15. Zelenetz AD, Wierda WG, Abramson JS, Advani RH, Andreadis CB, Bartlett N, et al. Non-Hodgkin's lymphomas, version 1.2013. J Natl Compr Canc Netw. 2013;11(3):257-72

16. Zelenetz AD, Abramson JS, Advani RH, Andreadis CB, Byrd JC, Czuczman MS, et al. NCCN Clinical Practice Guidelines in Oncology: non-Hodgkin's lymphomas. J Natl Compr Canc Netw. 2010;8(3):288-334.

17. Horwitz SM, Zelenetz AD, Gordon LI, Wierda WG, Abramson JS, Advani RH, et al. NCCN Guidelines Insights: Non-Hodgkin's Lymphomas, Version 3.2016. J Natl Compr Canc Netw. 2016;14(9):1067-79.

18. Andersen CJ, Dupree L, Murray K, Ragonesi N, McMullen K, Cintron-Rivera L, et al. Low-Density Lipoproteins, High-Density Lipoproteins (HDL), and HDLAssociated Proteins Differentially Modulate Chronic Myelogenous Leukemia Cell Viability. Lipids. 2020;55(6):615-26.

19. Choi S, Yoo YJ, Kim H, Lee H, Chung H, Nam MH, et al. Clinical and biochemical relevance of monounsaturated fatty acid metabolism targeting strategy for cancer stem cell elimination in colon cancer. Biochem Biophys Res Commun. 2019:519(1):100-5.

20. Cvetkovic Z, Milosevic M, Cvetkovic B, Masnikosa R, Arsic A, Petrovic S, et al. Plasma phospholipid changes are associated with response to chemotherapy in non-Hodgkin lymphoma patients. Leuk Res. 2017;54:39-46.

21. Downes DP, Daurio NA, McLaren DG, Carrington P, Previs SF, Williams KB. Impact of Extracellular Fatty Acids and Oxygen Tension on Lipid Synthesis and Assembly in Pancreatic Cancer Cells. ACS Chem Biol. 2020;15(7):1892-900.

22. Li J, Gu D, Lee SS, Song B, Bandyopadhyay S, Chen S, et al. Abrogating cholesterol esterification suppresses growth and metastasis of pancreatic cancer. Oncogene. 2016;35(50):6378-88.

23. Madak-Erdogan Z, Band S, Zhao YC, Smith BP, Kulkoyluoglu-Cotul E, Zuo Q, et al. Free Fatty Acids Rewire Cancer Metabolism in Obesity-Associated Breast Cancer via Estrogen Receptor and mTOR Signaling. Cancer Res. 2019; 79(10):2494-510
24. Mulas MF, Abete C, Pulisci D, Pani A, Massidda B, Dessi S, et al. Cholesterol esters as growth regulators of lymphocytic leukaemia cells. Cell Prolif. 2011; 44(4):360-71.

25. Cheng S, Wang G, Wang Y, Cai L, Qian K, Ju L, et al. Fatty acid oxidation inhibitor etomoxir suppresses tumor progression and induces cell cycle arrest via PPARgamma-mediated pathway in bladder cancer. Clin Sci (Lond). 2019;133(15):1745-58

26. Hanikoglu A, Kucuksayan E, Hanikoglu F, Ozben T, Menounou G, Sansone A, et al. Effects of Somatostatin and Vitamin C on the Fatty Acid Profile of Breast Cancer Cell Membranes. Anticancer Agents Med Chem. 2019;19(15): 1899-909.

27. Nguyen PA, Chang CC, Galvin CJ, Wang YC, Yeon An S, Huang CW, et al. Statins use and its impact in EGFR-TKIs resistance to prolong the survival of lung cancer patients: A Cancer Registry Cohort Study in Taiwan. Cancer Sci. 2020;111(8):2965-73.

28. Rink JS, Yang S, Cen O, Taxter T, McMahon KM, Misener S, et al. Rational Targeting of Cellular Cholesterol in Diffuse Large B-Cell Lymphoma (DLBCL) Enabled by Functional Lipoprotein Nanoparticles: A Therapeutic Strategy Dependent on Cell of Origin. Mol Pharm. 2017;14(11):4042-51.

29. Smyth L, Blunt DN, Gatov E, Nagamuthu C, Croxford R, Mozessohn L, et al. Statin and cyclooxygenase-2 inhibitors improve survival in newly diagnosed diffuse large B-cell lymphoma: a large population-based study of 4913 subjects. Br J Haematol. 2020;191(3):396-404.

30. Trotta F, Avena P, Chimento A, Rago V, De Luca A, Sculco S, et al. Statins reduce intratumor cholesterol affecting adrenocortical cancer growth. Mol Cancer Ther. 2020;19(9):1909-21.

31. Tutuska K, Parrilla-Monge L, Di Cesare E, Nemajerova A, Moll UM. Statin as anti-cancer therapy in autochthonous T-lymphomas expressing stabilized gain-of-function mutant p53 proteins. Cell Death Dis. 2020;11(4):274.

32. Peixoto J, Lima J. Metabolic traits of cancer stem cells. Dis Model Mech. 2018;11(8):dmm033464.

33. Amiri M, Yousefnia S, Seyed Forootan F, Peymani M, Ghaedi K, Nasr Esfahani $\mathrm{MH}$. Diverse roles of fatty acid binding proteins (FABPs) in development and pathogenesis of cancers. Gene. 2018;676:171-83.

34. Zhao L, Hao F, Huang J, Liu X, Ma X, Wang C, et al. Sex- and Age-Related Metabolic Characteristics of Serum Free Fatty Acids in Healthy Chinese Adults. J Proteome Res. 2020;19(4):1383-91.

35. Thanarajasingam G, Maurer MJ, Habermann TM, Nowakowski GS, Bennani NN, Thompson CA, et al. Low Plasma Omega-3 Fatty Acid Levels May Predict Inferior Prognosis in Untreated Diffuse Large B-Cell Lymphoma: A New Modifiable Dietary Biomarker? Nutr Cancer. 2018;70(7):1088-90.

\section{Publisher's Note}

Springer Nature remains neutral with regard to jurisdictional claims in published maps and institutional affiliations.

\section{Ready to submit your research? Choose BMC and benefit from:}

- fast, convenient online submission

- thorough peer review by experienced researchers in your field

- rapid publication on acceptance

- support for research data, including large and complex data types

- gold Open Access which fosters wider collaboration and increased citations

- maximum visibility for your research: over $100 \mathrm{M}$ website views per year

At BMC, research is always in progress.

Learn more biomedcentral.com/submissions 